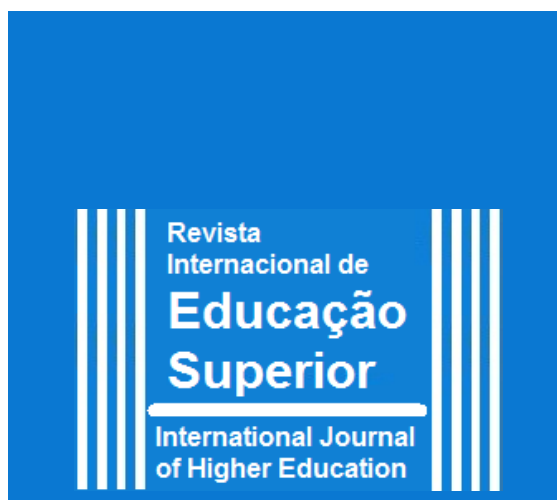

Correspondência ao Autor

${ }^{1}$ Solange Riato Prates

E-mail: solangeriato@hotmail.com

Universidade Federal do Mato Grosso do

Sul, Brasil

Submetido: 23 out. 2018

Aceito: 07 jan. 2019

Publicado: 31 jan. 2018

doiz 10.20396 /riesup.v5i0.8653753 e-location: e019030

ISSN 2446-9424

Checagem Antiplagiarismo

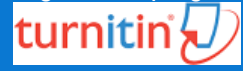

Distribuído sobre

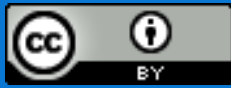

\section{Educação Superior e Relações de Gênero:} Atividades Domiciliares para Mães Estudantes de Pedagogia

Solange Riato Prates ${ }^{1}$ (D) Josiane Peres Gonçalves ${ }^{2}$ (D)

12 Universidade Federal do Mato Grosso do Sul

\section{RESUMO}

O presente estudo tem por objetivo investigar a realidade de mulheres que se tornaram mães enquanto cursavam Pedagogia, com ênfase para os desafios vivenciados por elas ao conciliar os estudos com a maternidade, bem como a postura da universidade em relação às atividades domiciliares e atendimento a essas alunas. A pesquisa foi realizada por meio de levantamento de informações na Secretaria Acadêmica da universidade e gravação de entrevistas com uma professora e três mulheres que se tornaram mães enquanto estudavam Pedagogia. Os resultados indicam que: apesar de as mulheres conquistarem espaço no mundo acadêmico, quando ocorre a gravidez elas se deparam com dificuldades, ficando acumuladas de atribuições; durante os três meses de licença maternidade, os professores enviam atividades domiciliares, mas as alunas consideram pouco tempo de afastamento; apesar dos desafios vivenciados pelas 34 mães acadêmicas, $91,16 \%$ do total deram continuidade ou conseguiram concluir a educação superior.

\section{PALAVRAS-CHAVE}

Mães estudantes. Licença maternidade. Universidade. 


\section{Higher Education and Gender Relations: Domiciliary Activities for Mothers Students of Pedagogy}

\section{ABSTRACT}

The present study aims to investigate the reality of women who became mothers while attending Pedagogy, with emphasis on the challenges they experienced in reconciling their studies with motherhood, as well as the university's attitude towards home-based activities and attendance to these students. The research was carried out through a survey of information in the Academic Secretary of university and recording interviews with a teacher and three women who became mothers while studying Pedagogy. The results indicate that: although women gain space in the academic world, when pregnancy occurs they face difficulties, accumulated with attributions; during the three months of maternity leave, teachers send home activities, but the students consider little time away; despite the challenges faced by the 34 academic mothers, $91.16 \%$ of the total gave continuity or were able to complete the higher education.

\section{KEYWORDS}

Students mothers. Maternity leave. University.

\section{Educación Superior y Relaciones de Género: Actividades Domiciliares para Madres Estudiantes de Pedagogía}

\section{RESUMEN}

El presente estudio tiene por objetivo investigar la realidad de mujeres que se convirtieron en madres mientras cursaban Pedagogía, con énfasis en los desafíos vivenciados por ellas al conciliar los estudios con la maternidad, así como la postura de la universidad en relación a las actividades domiciliares y atención a esas estudiantes. La investigación fue realizada por medio de levantamiento de informaciones en la Secretaría Académica del universidad y grabación de entrevistas con una profesora y tres mujeres que se convirtieron en madres mientras estudia Pedagogía. Los resultados indican que: a pesar de que las mujeres conquistan espacio en el mundo académico, cuando ocurre el embarazo se enfrentan a dificultades, quedando acumuladas de atribuciones; durante los tres meses de permiso de maternidad, los profesores envían actividades domiciliares, pero las alumnas consideran poco tiempo de alejamiento; a pesar de los desafíos vivenciados por las 34 madres académicas, el 91,16\% del total dio continuidad o consiguieron concluir el educación superior.

PALABRAS CLAVE

Madres estudiantes. Licencia de maternidad. Universidad. 


\section{Introdução}

A mulher na atualidade tem conquistado espaço no contexto social, sendo comum haver a existência de mulheres nas mais diversas ocupações, como estudantes, professoras, advogadas, donas de casa, gerentes de empresas, donas de empresa, etc. Entretanto, podemos perceber que a mulher ainda continua acumulada de funções, tendo que geralmente relacionálas com a maternidade.

Nesse contexto, a realidade investigada refere-se às mulheres estudantes universitárias que, após se tornarem mães e ficarem afastadas durante a licença maternidade, enfrentam dificuldades, por ter que realizar as atividades acadêmicas em casa, além de cuidar do bebê e desempenhar as funções domésticas. Muitas vezes, essas alunas, que se dividem entre as preocupações com as atividades acadêmicas, domésticas e maternidade, não conseguem assimilar os conteúdos das disciplinas da mesma forma que antes. E após o afastamento, as mães se deparam com o acúmulo de atividades acadêmicas a serem desenvolvidas, como estágios, elaboração de trabalhos, avaliações, etc, devendo cumprir da mesma forma que antes ou correm o risco de reprovação.

Sendo assim, sabendo que as mulheres mães enfrentam dificuldades em relação a sua formação acadêmica, mediante a realização do presente estudo, procurei buscar possíveis respostas para as seguintes indagações: Quais os principais desafios enfrentados pelas mulheres ao retornar a sua formação após o período de licença maternidade? Como conciliam a vida acadêmica depois que se tornaram mães? Como tem sido a postura do Campus de Naviraí Universidade Federal de Mato Grosso do SUL (CPNV/UFMS) em relação às atividades domiciliares e atendimento a essas alunas?

Cabe salientar que se trata de uma situação cada vez mais frequente em cursos universitários considerados femininos, como é o caso de Pedagogia (GUEDES, 2008; FERREIRA; SILVA, 2017), visto que muitas alunas estão na fase correspondente ao adulto jovem (de 20 a 40 anos), período mais adequado para a procriação, conforme Gonçalves (2016).

Assim, surgiu a necessidade de melhor entender essa realidade, por acreditar que é necessário saber como essas mães estudantes se organizam e superam os desafios, a fim de evitar que tenham muitas desistências devido à licença maternidade.

Baseando-se no que foi exposto, destaco que o objetivo do presente estudo é investigar a realidade de mulheres estudantes universitárias que se tornaram mães enquanto cursavam Pedagogia no Campus de Naviraí da Universidade Federal de Mato Grosso do Sul (CPNV/UFMS), destacando os desafios vivenciados por elas ao conciliar os estudos com a maternidade, bem como a postura da UFMS em relação às atividades domiciliares e atendimento a essas alunas. 
A relevância na realização da pesquisa se justifica no sentido de contribuir com o processo de formação acadêmica das mulheres que passam pela experiência da maternidade enquanto frequentam a educação superior. Os resultados da pesquisa poderão ajudar a instituição e profissionais da educação a melhor compreender essa realidade vivenciada pelas mães estudantes, podendo contribuir também com a comunidade científica, no sentido de ampliar o conhecimento acerca dessa temática investigada.

Para a realização da pesquisa, a metodologia utilizada se caracterizou por estudos bibliográficos, pautados em autores que abordam o assunto e pela pesquisa de campo de natureza quanti e qualitativa. A coleta de dados foi realizada a partir de levantamento junto à Secretaria Acadêmica do Campus de Naviraí da Universidade Federal de Mato Grosso do Sul (CPNV/UFMS), para saber quantas alunas já se tornaram mães durante a graduação em Pedagogia e também foram gravadas entrevistas com três estudantes que vivenciaram a experiência da maternidade e uma professora do referido curso de educação superior. Os resultados serão apresentados logo após a apresentação da abordagem teórica.

\section{Mulheres X Maternidade: Realizações e Conflitos}

Quando o assunto é maternidade, é possível perceber que se trata de algo que é muito valorizado na sociedade e nos mais diversificados meios de transmissão de valores, surgindo assim alguns questionamentos: Será que a maternidade é considerada satisfatória para todas as mulheres? Após o nascimento do bebê, tudo se resume em alegria para a mãe? A ideia de que a maternidade é uma importante forma de realização feminina pode estar relacionada com fatores culturais, visto que as meninas desde pequenas são educadas para se tornarem mães, conforme destaca Azevedo (2006, p. 269):

\footnotetext{
Desde a infância as meninas treinam o papel de boa mãe, segundo o qual a mulher deve ser capaz de enormes sacrifícios, entre eles ser amável, tranquila, compreensiva, terna, equilibrada, acolhedora, feminina em tempo integral! Esperase um ideal, um modelo de mãe perfeita, uma imagem romanceada da maternidade construída ao longo dos últimos séculos, que está alicerçada sob um rígido padrão incapaz de admitir qualquer vestígio de sentimentos ambivalentes nas mães.
}

Observa-se que, com o nascimento de um filho, a maior parte das mulheres passa por sentimentos contraditórios e incompatíveis com a imagem idealizada da maternidade predominante em diversos contextos culturais. Acontece que as várias mudanças podem ocasionar em desequilíbrio e alterações de identidade devido as grandes expectativas da maternidade predominantes na sociedade. Neste sentido, “[...] supõe-se que a mulher, por ser quem gera os filhos, desenvolve um amor inato pelas crianças e fica sendo a pessoa melhor capacitada para cuidar delas" (FALCKE; WAGNER, 2000, p. 9). Percebe-se assim que culturalmente os conceitos gerais relativos à maternidade estão fortemente calcados no mito da mãe perfeita. 
Essa obsessão de acreditar que a maternidade é "natural" entra em contradição com a vivência da maternagem que pode resultar em um sentimento de "mãe desnaturada" causando assim muito sofrimento. Porém, esse fato tem conduzido muitas mulheres na atualidade a questionarem aspectos relativos ao que fazem, pensam, sentem e então avaliar suas próprias experiências, procurando tornar menos rígido o padrão determinista idolatrado socialmente. Dessa forma, Azevedo (2006, p. 270) enfatiza que:

O problema, porém, é que as mulheres de hoje, já não são preparadas, não sabem e nem querem cuidar dos seus filhos como suas mães faziam. Elas têm outros interesses, desejos, informações, expectativas e, sobretudo outras alternativas para se realizarem como mulher, que não estão mais restritas à maternidade.

Trata-se de uma mudança de comportamento feminino, influenciado pelas diversas conquistas obtidas pelas mulheres na sociedade. Muitas percebem que é mais interessante desenvolver outras funções do que cuidar dos filhos, principalmente por se tratar de uma atividade prazerosa, mas também exaustiva. Por outro lado, muitas mães se sentem culpadas por terem que ficar muito tempo afastadas de seus filhos, devido às atividades profissionais, bem como de estudantes. Mas é importante lembrar que os ideais de maternidade da atualidade não são os mesmos de outros contextos históricos e sociais.

Conforme Badinter (1985), apesar do sentimento de culpa que as mulheres, em virtude da crença generalizada de que a maternidade é de responsabilidade da natureza feminina, é preciso considerar que em séculos anteriores não tinham a mesma propriedade e a mesma influência que passou a ter do século XIX em diante, embora a mulher seja uma figura histórica considerada com capacidades de almejar e simbolizar.

Observa-se que pelo fato de a sociedade acreditar nas ideias que foram culturalmente atribuídas as mulheres em relação a maternidade ao longo da história, muitas são acusadas frequentemente de anormais, gerando sentimento de culpa e intimidações, quando optam por não ter filhos, sendo até mesmo excluída, pois acredita-se que o fato de ser tornar mãe seja inata ao feminino. Porém, a autora discorre que esses sentimentos não existiam em épocas passadas.

Para convencer as mulheres de que seria importante elas cuidarem de seus filhos Badinter (1985) destaca que o aumento da mortalidade devido ao fato de serem entregue as ama-de-leite era maior, e a mortalidade das crianças amamentadas por suas verdadeiras mães era duas vezes menor do que as crianças amamentadas pelas amas-de-leite. Para Costa (1983, p.256), “[...] o mais provável, porém, é que as mães ignorassem que a amamentação materna fosse vital à sobrevida dos filhos”. Nesse sentido, Badinter (1985, p. 211) destaca:

A vigilância materna se estendeu de maneira ilimitada. Não havia hora do dia ou da noite em que a mãe não cuidasse sozinha, carinhosamente de seu filho. Quer estivesse em boa saúde ou doente, ela devia permanecer vigilante. Se, porém, ela adormecia, estando o filho enfermo, eis que se sentia culpada do maior dos crimes maternos: a negligência. 
Embora a mulher seja uma figura histórica atribuída de capacidades de desejar e simbolizar, o assunto maternidade ainda mobiliza emocionalmente praticamente todas as mulheres, pois elas sabem que não ter filhos por opção ou devido a outras circunstâncias, acarreta não realizar uma competência, desviando-se de um padrão que se cumpre de século à século, implantando uma série e incômoda diferença (MANSUR, 2003).

Por tratar-se de um padrão cultural fortemente internalizado, a mulher sem filhos costuma enfrentar seus próprios sentimentos e o olhar dos outros, uma vez que, segundo Pravaz (1981, p. 97), “[...] encerra um mistério não revelado em seu interior, não se mostrou por dentro, não chegou a 'saber-se' por inteiro". Em geral, a sociedade compreende que a maternidade faz com que as mulheres se sintam completas por reproduzirem hábitos antepassados de gerar e parir. Porém, Mansur (2003) destaca que as mulheres esperam ter filhos de preferência sadios, estabelecendo sua aceitabilidade no mundo feminino e ocupando o lugar para ela reservado no contexto sociocultural.

É possível perceber que a questão maternidade faz parte do universo feminino, gerando muitos conflitos nas mulheres: se têm filhos há o sentimento de culpa por não ser a mãe idealizada, se não tem, há as cobranças sociais e a percepção de que não se sentirá completa. Assim, em muitas situações, a dúvida feminina vai além da opção de ter ou não filhos, visto que é preciso decidir sobre o momento que considerado mais adequado para ter um filho, como sinaliza Scott (2012, p. 36):

Para as mulheres que desejam ter filhos, o dilema atual é: quando? As mulheres
enfrentam a questão da premência da idade (fator biológico) e sua vontade de
investir nos estudos e na carreira, adiando a gravidez. O "relógio biológico" insiste
em andar mais rápido do que muitas gostariam e a gravidez em idade mais avançada
continua a ser mais problemática em termos médicos. Assim, se nas décadas de
1960 e de 1970 a contracepção estava no centro das preocupações reprodutivas,
atualmente ela divide espaço com as técnicas concepção, a grande aposta de muitas
mulheres que postergam a maternidade.

Realmente a maternidade pode ser entendida como um conflito para as mulheres modernas que pretendem estudar e investir na carreira profissional. Apesar dos avanços da medicina e do aumento da perspectiva de vida da população, o período adequado para a reprodução feminina seria dos 20 aos 35 anos. Algumas mulheres se tornam mães antes, sendo considerada gravidez na adolescência, outras têm filhos após os 40 anos, mas já é considerado fator de risco, inclusive com maior probabilidade de o bebê nascer com alguma deficiência. Dessa forma, se uma mulher tiver uma vida longa, que atinja os cem anos de idade, ela teria em torno de duas décadas para procriar, justamente no período em que está estudando ou construindo uma carreira profissional.

Por outro lado, essa dimensão temporal implica em outro fator relacionado à maternidade, a educação escolar e a carreira profissional: a percepção das mulheres de que, conforme Mansur (2003), a imagem fixa da maternidade-fecundidade não lhes convém, pois são mães transitoriamente, enquanto o fato de serem mulheres é perdurável. Ao considerar ou aumento da perspectiva e que as pessoas têm condições de viverem por mais tempo, as 
funções relativas à maternidade são predominantes enquanto os filhos são dependentes, porque ao se tornarem adultos, tendem a seguir seus próprios caminhos. Dessa forma, a condição de ser mulher perdura para a vida toda, enquanto que a maternidade passa por situações diferentes, desde a total dependência dos filhos até a sua autonomia, período em que, embora existindo vínculos afetivos, os filhos não dependem mais dos cuidados maternos.

Ao analisar a questão da maternidade com a carreira profissional, Scott (2012) reflete sobre as escolhas que as mulheres precisam fazer para conseguir desempenhar ambas as funções: maternas e profissionais.

\begin{abstract}
Do ponto de vista das escolhas individuais, as mulheres enfrentam não só o impasse "carreira versus maternidade", mas também a decisão de não ter filhos definitivamente ou adiar sua vinda, valendo-se, para isso, das várias técnicas de concepção fertilização oferecidas hoje em dia: fertilização in vitro (FIV), congelamento dos óvulos, ovodoação, barriga de aluguel. Outra consideram a alternativa de deixar de trabalhar, ou pelo menos trabalhar em outras bases - por conta própria, por exemplo, abrindo seu próprio negócio - para poder ter ou cuidar de seus filhos (SCOTT, 2012. p. 36).
\end{abstract}

Segundo a autora, torna-se complicado demonstrar neste início do século XXI um perfil para o público feminino, por parte de uma grande adversidade presente entre as mulheres no Brasil, como vem sendo indicado. No entanto, os números ajudam a mapear alguns aspectos como escolaridade, faixa etária, "raça" ou cor, como aponta Scott (2012. p. 34):

Esse indicador esconde importantes desigualdades, especialmente se for considerado o quesito escolaridade, o número médio de filhos é quase o dobro $(3,2$ filhos) daquelas que têm oito anos ou mais de estudos (1,7 filhos em média). Entre os motivos que podem explicar esses comportamentos diferenciados em relação a média de filhos entre as mulheres mais escolarizadas, poderíamos elencar o fato de elas podem ter mais informações e acesso a meios contraceptivos mais eficazes, incluindo o uso adequado de anticoncepcionais; o interesse de investir em sua carreira profissional, o que lhes abriria outras perspectivas de futuro; assim como de fato de conseguirem planejar a gravidez evitando a ocorrência da gestação numa etapa de vida inoportuna.

Observa-se que o grau de escolaridade tem fortes influências na idade em que a mulher tem filhos: mais instrução, maternidade mais demora. As mulheres com oito anos de estudos têm filhos perto dos 28 anos, enquanto as menos escolarizadas têm filhos com pouco mais de 25 anos.

Com a ampliação do ensino médio e universitário, facilitou o aumento da escolaridade feminina em diferentes categorias e áreas de conhecimento. Matos e Borelli (2012) salienta que entre 1970-1975, por exemplo, o número de mulheres nas universidades aumentou cinco vezes, ao mesmo tempo em que o de homens dobrou. Nas décadas seguintes, o progresso das mulheres aumentou, transformando-as economicamente mais competitivas e aptas para encarar resistências e preconceitos, além de aumentar sua presença em setores até então impossível ao público feminino. Ao refletir sobre essas questões, Matos e Borelli (2012, p. 145) consideram que: 
Apesar de a presença feminina nas universidades ainda se concentrar nas áreas de Educação e Humanidades, observar-se ainda se a diversificação, com as mulheres presentes em outros campos como as Engenharias, a Arquitetura, a Medicina, a Veterinária e o Direito, numa sistemática consolidação de novas trajetórias profissionais.

Tomando como base esta perspectiva, Matos e Morelli (2012) ressalta que a educação feminina é vista como fundamental para a independência das mulheres, tornando-se ponto de destaque da atuação feminina que trabalhavam, fazendo com que tivessem os mesmos direitos aos dos homens, desde os meios para o exercício de trabalho e a remuneração.

\section{As Mulheres Mães em Contexto da Educação Superior}

Ter um filho é o sonho de quase todas as mulheres, porém isso pode trazer grandes transformações em vários aspectos, pois a maternidade geralmente é uma experiência única na vida de qualquer mulher, como sinaliza Tourinho (2006, p. 25): .

[...] devido ao papel ideal que a sociedade impôs sobre as mulheres de assumirem seus filhos por obrigação, de terem obrigatoriamente um perfil materno, elas podem sofrer certa culpa caso não consigam dar conta de ser mãe. Se a mulher decide ser, todos os relacionamentos com as pessoas que vivem ao seu redor vão mudar. Há uma nova identidade da mulher agora: ser mães.

Em nossa sociedade, toda mãe é considerada como papel essencial para o desenvolvimento do bebê, visto que ele nasce inteiramente dependente dos adultos para sobreviver. Um pensamento como esse evidencia que "Pelo fato de os seres humanos serem notavelmente vulnerável e de crescimento lento, eles exigem um período longo de apoio físico e emocional" (BEE, 1997, p. 425). Esses fatos sugerem que é necessário haver a presença das mães junto de seus bebês nos primeiros meses de vida, porém nem sempre é assim que acontece.

No caso das mães que desempenham outras atividades sociais, como de estudantes ou profissionais, elas precisam aprender a conviver com uma nova realidade que desconheciam. Então, como conciliar a maternidade e a vida acadêmica? Esse é o grande desafio para as mulheres que se tornam mães durante a sua graduação. Conforme Costa (2008, p. 30), "[...] as mães universitárias sofrem por sua maternidade durante a graduação e muitas vezes acabam atrasando ou até mesmo paralisando o curso para poderem cuidar de seus filhos, principalmente pelo fato de não terem onde deixá-los”.

Em uma reportagem, Sant'Anna (2006) descreve o que poderia ser uma opção para mães estudantes: ao entrevistar uma mulher, ela declara ter optado por um curso superior à distância, por não atrapalhar a sua vida profissional e nem o tempo que passaria com o seu filho. Portanto, diante de grandes dificuldades em ajustar a vida acadêmica, a maternidade e a vida profissional, muitas dessas mulheres buscam como alternativa o ensino à distância, entendendo tratar-se de uma opção para resolver esse problema. 
Ao entrevistar universitárias que tiveram filhos enquanto cursavam o nível superior, Lima (2007) destaca alguns dos problemas que as mães tiveram com a chegada da criança e a conciliação com os estudos. Os resultados apontam que, em sua maioria, as mães param a educação superior com a intenção de retornar posteriormente, contando com possíveis colaborações de familiares para cuidar de seus filhos enquanto elas estudam.

A opção de parar os estudos e voltar depois que a vida materna estiver estabilizada nem sempre é o que realmente acontece, pois com o tempo, vão surgindo novos obstáculos e dificuldades que acabam desanimando essas mulheres, a ponto de desistirem definitivamente da trajetória acadêmica.

Assim, é possível questionar: Quais são os desafios encontrados ao retornar da licença maternidade? Entende-se que uma das maiores dificuldades no retorno à vida acadêmica, há uma questão relevante que deve ser levada em consideração: o nível do rendimento escolar acaba sendo inferior quanto a aprendizagem com relação aos de conteúdos que se apresentam, ou seja, após esse período de distanciamento formativo elas não conseguem aprender o que é ensinado, muitas vezes, encontrando dificuldade de compreender os saberes universitários devido a esse afastamento e a nova função de ser mãe acadêmica.

Quanto aos direitos das estudantes universitárias que passam pela experiência da maternidade, existem legislações que amparam as alunas, no sentido de poderem ficar três meses afastadas da universidade, sem haver problemas com frequências. Entretanto, a licença maternidade para mulheres que trabalham fora é de quatro meses, podendo chegar a seis meses se a mulher for funcionária pública, como mencionam Rodrigues e Ferreira (2008, p. $15)$ :

Uma incongruência nos lapsos temporais previstos pode ser constatada nas leis mencionadas. Enquanto a Constituição Federal assegurou às trabalhadoras gestantes um período de afastamento consistente em 120 dias, a legislação educacional garantiu apenas 90 dias (3 meses) às estudantes gestantes, o que não possui justificativa plausível.

Enquanto a Constituição Federal de 1988 prevê 120 dias de afastamento, a legislação educacional garante apenas 90 dias, tal situação acaba ferindo um dos direitos constitucionais da mulher e mãe acadêmica. Por outro lado, tendo em vista que em muitas universidades os cursos são semestrais, dependendo do período em que ocorre o início e fim da licença maternidade, correria o risco de a aluna ficar praticamente o semestre inteiro afastada, comprometendo assim a sua aprendizagem e seu rendimento acadêmico.

A lei que ampara a questão educacional e a estudante gestante, regulamentando o tempo de afastamento da gestação, é a Lei Federal № 202, de 17 de abril de 1975, a qual efetivou o regime de exercícios domiciliares, estabelecido pelo Decreto-Lei n. ${ }^{\circ} 1044$, de 21 de outubro 1969. Após o nascimento do bebê, inicia-se o processo de atividade domiciliar, em que a mãe acadêmica realiza seus estudos fora da instituição de educação superior, cabendo aos professores tutoriar essas atividades e também oferecer o suporte necessário. 
A Lei n. ${ }^{\circ}$ 6.202/75 estabelece, no Art. $1^{\circ}$, que a partir do oitavo mês de gestação e durante três meses, a estudante em estado de gravidez ficará assistida pelo regime de exercícios domiciliares, instituído pelo Decreto-lei número 1.044, 21 de outubro de 1969 (BRASIL, 1975).

Observa-se que existem Leis que regulamentam e norteiam a prática do regime domiciliar em cada universidade, os quais discorrem sobre o direito que essas mães acadêmicas possuem em relação ao afastamento, podendo substituir as aulas não frequentadas por elas durante esse período de licença maternidade, por atividades domiciliares, porém cabe a cada uma das instituições de educação superior criar suas próprias regulamentações. Nesse sentido, o Conselho de Ensino de Graduação da Universidade Federal de Mato Grosso do Sul, por meio da Resolução n 104, de 16 de Julho de 2010, Art. 2º estabelece que "A partir do oitavo mês de gestação, a acadêmica gestante poderá ser assistida pelo regime de exercícios domiciliares com duração de três meses consecutivos" (UFMS, 2010. p. 1).

Quanto ao apoio por parte dos professores e das instituições, é dever de todos oferecer o suporte necessário, conforme as leis citadas anteriormente. Assim, torna-se importante que coordenadores de curso, professores e funcionários da universidade desempenhem esse papel de apoio às mães acadêmicas, para que não desistam do seu processo de formação, visto que essas estudantes do gênero feminino necessitam de um apoio maior nesse período transitório de suas vidas.

\section{Metodologia}

Para a realização da pesquisa, além da abordagem teórica descrita anteriormente, foi realizada também uma pesquisa de campo de natureza quantitativa e qualitativa. Para Sampieri, Collado e Lucio (2006), a pesquisa que contempla dados quanti e qualitativos é chamada de mista ou multimodal, tem a possibilidade de convergir ambos os enfoques e aproveitar suas vantagens. Assim, os dados quantitativos neste estudo são mais gerais, para ter noção da quantidade de alunas que se afastam por licença maternidade no curso de educação superior investigado e se elas retornaram ou desistiram da faculdade. Já os dados qualitativos resultam das perspectivas das participantes da pesquisa sobre o tema pesquisado, pois, conforme Creswell (2010, p. 43), a abordagem qualitativa é caracterizada como "[...] um meio para explorar e para entender o significado que os indivíduos ou grupos atribuem a um problema social ou humano".

A pesquisa de campo foi realizada no CPNV/UFMS, sendo priorizado o curso de Pedagogia, implantado no ano de 2009, juntamente com o referido Campus (UFMS, 2008). Considerando que a referida graduação é composta majoritariamente por estudantes do gênero feminino, e que é muito frequente haver estudantes grávidas, foi feita a opção por investigar somente este curso de educação superior, que funciona no período noturno. 
Cabe salientar que o CPNV/UFMS oferta 60 vagas anuais para o curso de Pedagogia, mas em 2009 a turma tinha apenas 36 alunos matriculados. Nos anos seguintes, as vagas foram preenchidas, porém como ocorre um processo de desistências, trancamentos e transferências, as turmas de $1^{\circ}$ ao $4^{\circ}$ ano do curso costumam ter em média 40 estudantes, sendo a maioria do gênero feminino.

Para a realização da pesquisa de campo, foi feita a opção por coletar os dados de três diferentes formas: a) levantamento na secretaria acadêmica para identificar quantas alunas já tiveram afastamentos relativos à licença maternidade desde a implantação do curso e do CPNV em 2009 até o mês de novembro de 2017; b) entrevistas com três alunas que tiveram filhos, sendo que uma continuava afastada, outra já tinha retornado e continuava estudando e outra que desistiu da faculdade após o nascimento do filho; c) entrevista com uma professora que por duas décadas atuou como professora de educação superior, mais especificamente no curso de Pedagogia, e que acompanhou a experiência das mães acadêmicas que se afastaram e realizaram atividades domiciliares e também passou pela experiência de ter dois filhos quando era estudante.

Dessa forma, participaram da pesquisa quatro mulheres: três estudantes de pedagogia da UFMS/CPNV e uma professora do referido curso, conforme Quadro 1. Os nomes utilizados são fictícios, para preservar a identidade das participantes.

Quadro 1. Perfil dos participantes da pesquisa.

\begin{tabular}{|c|c|c|c|c|c|}
\hline Participantes & Idade & Profissão & $\begin{array}{c}\text { Filho (s) quando } \\
\text { estudava }\end{array}$ & $\begin{array}{l}\text { Ficava com o bebê } \\
\text { enquanto estudava }\end{array}$ & $\begin{array}{l}\text { Planejamento } \\
\text { da gravidez }\end{array}$ \\
\hline SARAH & 31 anos & Do lar & Primeiro filho & Esposo & $\begin{array}{c}\text { Não } \\
\text { planejada }\end{array}$ \\
\hline HELOISA & 25 anos & Parlamentar & Primeiro filho & Esposo & Planejada \\
\hline LÍVIA & 26 anos & Do lar & Primeiro filho & Mãe, pai e esposo & $\begin{array}{c}\text { Não } \\
\text { planejada }\end{array}$ \\
\hline $\begin{array}{l}\text { PROF. } \\
\text { GABRIELA }\end{array}$ & 46 anos & $\begin{array}{l}\text { Professora } \\
\text { Universitária }\end{array}$ & $\begin{array}{l}\text { Segundo e terceiro } \\
\text { filho }\end{array}$ & $\begin{array}{l}\text { Esposo, sogro, } \\
\text { madrasta e tia }\end{array}$ & $\begin{array}{c}\text { Não } \\
\text { planejada }\end{array}$ \\
\hline
\end{tabular}

Fonte: Autoras (2018).

Quanto ao procedimento para a realização da pesquisa de campo, foi feito contato inicial com a secretaria acadêmica do CPNV/UFMS e então pesquisado, junto ao livro de protocolo, as solicitações de atividades domiciliares devido à licença maternidade. Com as alunas e professora, foi feito contato, agendado um horário e então realizada a gravação das entrevistas na própria universidade ou na casa das participantes, sempre considerando o que era mais adequado para elas. Durante a coleta de dados, as participantes assinaram um Termo de Consentimento Livre e Esclarecido (TCLE), em que autorizavam a divulgação e publicação dos dados da pesquisa. 
Por fim, os dados quantitativos e qualitativos obtidos por meio da realização da coleta de dados, foram organizados, sistematizados e analisados, sendo fundamentados em outros estudos relacionados, conforme apresentados na sequência.

\section{Dados Quantitativos Sobre Estudantes de Pedagogia que Tiveram Filhos}

Desde a implantação do curso de Pedagogia, juntamente com o CPNV/UFMS, em 2009, até novembro de 2017, foi constatado que 34 alunas de Pedagogia tiveram filhos e fizeram atividades domiciliares, sendo possível perceber o percentual anual por meio do Gráfico 1.

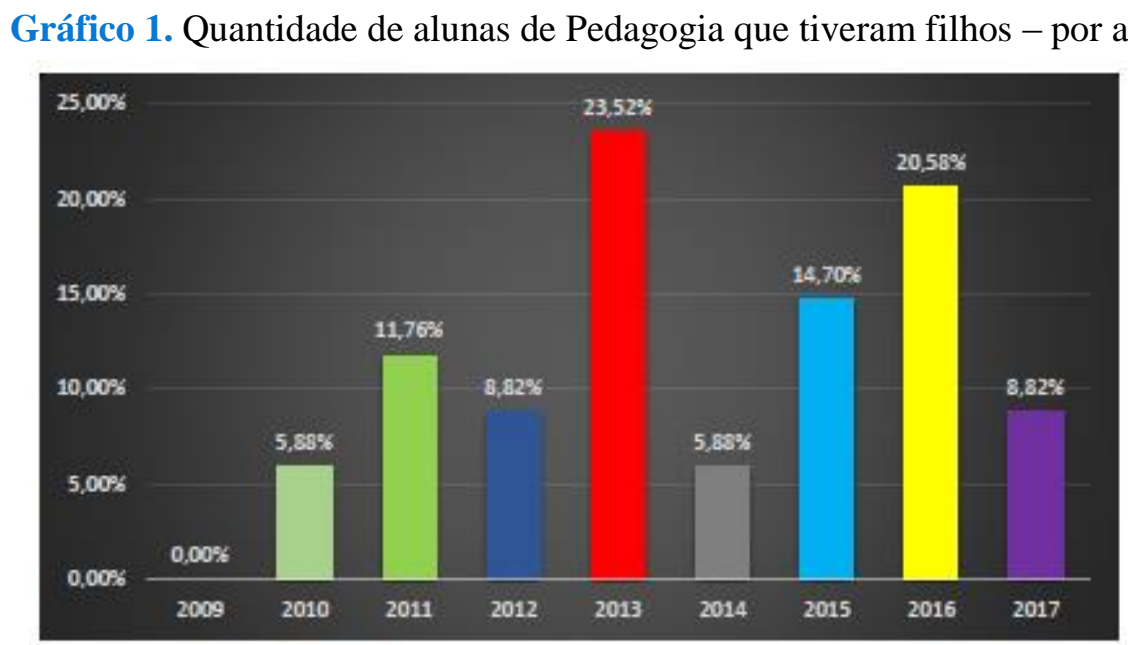

Fonte: Autoras (2018).

É possível notar que 2013 foi o ano que mais teve alunas que se tornaram mães, totalizando 8 casos ou 23,52\% do total, seguido por 2016 com 7 casos ou 20,58\%. Em 2015 foram 5 afastamentos ou 14,70\%; 2011 foram 4 afastamentos ou 11,76\%; 2012 e 2017 foram 3 afastamentos ou 8,82\%; 2010 e 2014 foram 2 casos ou 5,88\%. Somente em 2009 é que não houve casos de afastamento para o regime de atividades domiciliares, devido à licença maternidade, mas é importante considerar que a universidade encontrava-se em fase de implantação e havia apenas uma turma de Pedagogia com 36 discentes. A partir de 2012, o CPNV/UFMS passou a ter as quatro turmas do curso de licenciatura pesquisado e, desde então, 2014 foi o ano que proporcionalmente houve um menor número de afastamentos para licença maternidade.

Cabe salientar que os resultados expostos foram considerados até novembro de 2017, quando foi finalizada a coleta de dados quantitativa. Porém, em contato com as quatro turmas de Pedagogia, foi percebido que havia quatro alunas grávidas, mas que não foram consideradas para este estudo, por elas ainda não terem solicitado o afastamento para a realização de atividades domiciliares. 
Outras situações que frequentemente são percebidas no CPNV/UFMS, inclusive no ano de 2017, é que existem alunas grávidas frequentando o último semestre de educação superior em Pedagogia, mas que não chegam a solicitar as atividades domiciliares, por finalizar as exigências da graduação, bem como a Colação de grau, antes do nascimento do bebê. Por outro lado, existem casos de alunas que entram para a faculdade logo após o nascimento da criança, as quais devem encarar os mesmos desafios de conciliar as atividades acadêmicas com a maternidade, mas essas também não foram contadas para este estudo, por ser priorizado somente os casos que tiveram filhos e realizaram atividades domiciliares quando estavam matriculadas e frequentando o curso de Pedagogia do CPNV.

Um fato bastante positivo, que foi percebido a partir do levantamento dos dados quantitativos, é que a maioria das alunas que passam pela experiência de ter filhos, durante a graduação em Pedagogia, dá continuidade aos estudos e consegue concluir a educação superior, conforme demonstrado no Gráfico 2.

Gráfico 2. Situação das mães estudantes após o período de licença maternidade

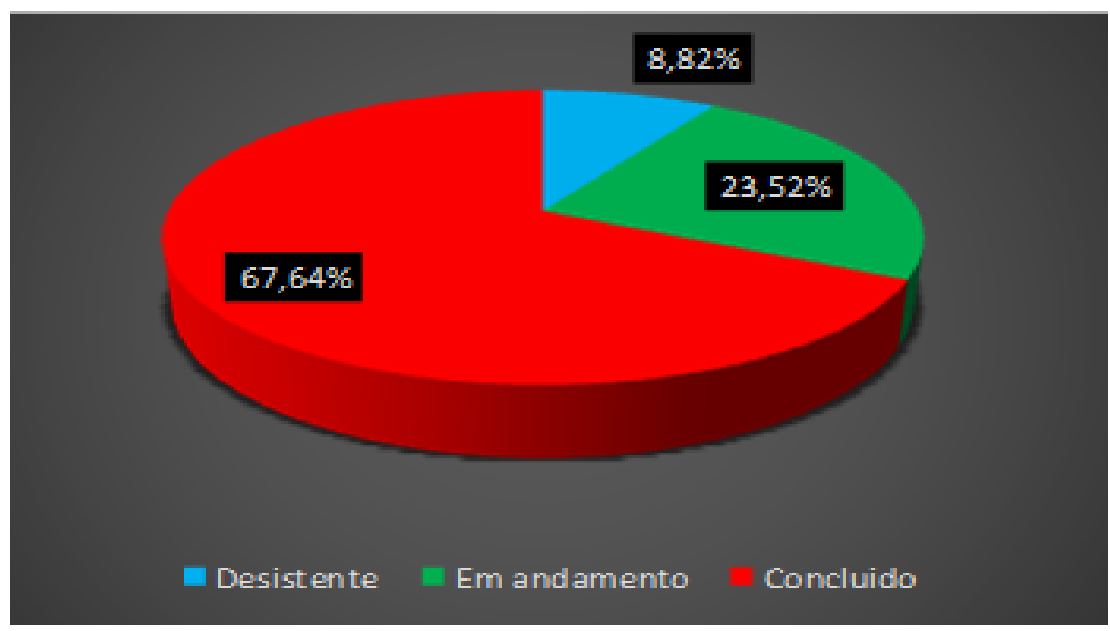

Fonte: Autoras (2018).

É possível notar, mediante análise do Gráfico 2, que 67,64\% das acadêmicas que solicitaram a licença maternidade, durante os anos de 2009 à novembro de 2017, concluíram a educação superior, $23.52 \%$ continuava em andamento e apenas 8,82\% desistiram. Ou seja, em um total de 34 mulheres que se tornaram mães enquanto cursavam Pedagogia, 91,16\% retornaram para a universidade e continuaram com os seus estudos, mesmo tendo que conciliar as atividades acadêmicas aos cuidados com o bebê, além de diversas outras atribuições que culturalmente são atribuídas ao gênero feminino.

Tal fato evidencia que, por maiores que tenham sido as dificuldades e desafios vivenciados pelas mães estudantes, a maioria consegue encarar a nova vida e prosseguir com o seu processo de formação profissional. Vale lembrar que, em alguns casos, para não precisar desistir da universidade, algumas mães estudantes trancam algumas disciplinas durante a fase do nascimento do bebê, para conseguir realizar as atividades acadêmicas e dispensar a atenção necessária ao filho. Nesse caso, elas demoram um pouco mais para 
finalizar a educação superior, mas é a forma encontrada para, com determinação, atingir o grau acadêmico desejado. De acordo com Barbosa e Rocha-Coutinho (2007), as mulheres com foco em sua profissionalização, na maioria das vezes, não interrompem a trajetória devido à licença maternidade, mas passam a entender que tanto a profissão quanto os cuidados para com o bebê exigem muita dedicação.

Se existem muitas mulheres que mantêm o foco na formação e profissão, mesmo diante do nascimento dos filhos, existem alguns casos que priorizam ficar mais tempo com a criança e talvez tenha sido esse o motivo pelo qual, 3 entre o total de 34 mulheres estudantes de Pedagogia do CPNV/UFMS (correspondente a 8,82\%), desistiram do curso de graduação. Ainda assim, esse número de desistentes pode ser considerado baixo, diante do número de concluintes ( 23 do total de 34 ou 67,64\%), bem como das que continuavam em andamento (8 mulheres ou $23,52 \%)$.

Trata-se de diferença significativa, e bastante positiva, ao comparar o número de mulheres que continua com os estudos e quem desiste porque, apesar de todas as dificuldades vivenciadas pelas mães acadêmicas (conforme apresentadas na sequência, mediante resultados da pesquisa qualitativa), elas foram persistentes e não mediram esforços para dar continuidade e concluir a educação superior.

\section{Perspectiva das mães estudantes de Pedagogia}

Antes de analisar os relatos das três estudantes entrevistadas, é importante considerar algumas características de cada uma delas. Embora havendo muitas alunas de Pedagogia que atendiam aos critérios da pesquisa, foi feita a opção por priorizar uma que já tinha retornado do período de licença maternidade e continuava os estudos, uma que estava de licença maternidade no momento da gravação das entrevistas (nos meses de junho e julho de 2017) e outra que desistiu do curso depois que o bebê nasceu.

Sarah é a mãe que continuava os estudos após o período de licença maternidade, tinha 31 anos, era seu primeiro filho e estava cursando o sétimo semestre de Pedagogia, fazendo apenas pesquisa de conclusão de curso. Morava com seu marido e sua filha e não estava trabalhando fora de casa. Em relação à decisão de ter filhos, Sarah menciona que a gravidez não foi planejada e durante o período de licença maternidade quem ajudava a cuidar do bebê, para que pudesse fazer os trabalhos solicitados pelos professores, era seu esposo "A única pessoa que me ajudou foi meu esposo [...] principalmente durante a noite!” (SARAH).

Lívia tinha 26 anos, morava com sua filha e seu esposo. Quando foi gravada a entrevista continuava afastada pelo regime de licença maternidade e estava cursando o terceiro semestre de Pedagogia. Ela também não trabalhava fora de casa. Lívia salienta que a gravidez não foi planejada, seus pais e esposo a ajudaram nos cuidados para com o bebê para que ela pudesse realizar os trabalhos acadêmicos. 
Já Heloisa foi à única mãe que planejou ter o filho, visto que, por ser casada há algum tempo, ela e o esposo desejavam ter filho. Porém, Heloisa foi quem desistiu do curso de Pedagogia por considerar muito difícil conciliar a nova vida de mãe com os estudos. "Olha o período em que eu estava grávida, e como eu trabalhava durante o dia, eu chegava em casa e as vezes eu queria descansar e tinha que ir para a faculdade, foi meio complicado!"

Heloisa estudou até o terceiro semestre e desistiu da educação superior, após tornar-se mãe, porque afirma ter vivenciado sentimentos contraditórios em relação à maternidade, optando assim por se dedicar somente aos cuidados do bebê. Ao refletir sobre como as mulheres se sentem ao se tornarem mães, Parker (1997) destaca que a experiência da maternidade costuma vir acompanhada de sentimentos ambivalentes, às vezes bons e às vezes ruins, os quais são experienciados pela grande maioria do público feminino que tem filhos pequenos.

Ao relatar sobre as dificuldades no processo de se tornarem mães durante a graduação, as estudantes de Pedagogia mencionaram que tiveram alguns contratempos, havendo a necessidade de trancar o curso, no caso de Sarah, ou desistir da faculdade, no caso de Heloisa.

O problema veio depois que a bebê nasceu! Conciliar todo o processo da faculdade, todo o calendário com o bebê. [...] A chegada de um bebe deixa tanto a casa da gente quanto a alma da gente tudo embaraçada né!? (risos). Trás umas alegrias, mas também trás bastantes problemas (SARAH).

Realmente é tentar reconciliar as duas coisas, fazer os trabalhos tudo em dia para entregar, é muito difícil! Ainda mais com eles recém nascidos, eles tomam todo o tempo [...] a minha no primeiro mês só chorava! (LÍVIA)

Depois que a bebê nasceu fui desanimando, fui perdendo a vontade de ir para a faculdade, ficava com dó de deixar ela em casa, eu também não tinha tanto apoio! Se fosse coisa que eu pudesse contar com alguém que eu estaria na faculdade e ela estaria bem seria diferente, foi bem complicada essa situação (HELOISA).

Diante dos relatos é possível perceber a existência do sentimento de ambivalência emocional, característico de uma vivência existente em relação a uma pessoa ou situação. No caso dessas mulheres, as dificuldades surgiram ao se tornaram mães durante a graduação, devido a falta de habilidade para compreender e pensar acerca de suas emoções e sentimentos. Para Touro (2002), é mediante a afetividade que nos identificamos com as outras pessoas e assim nos tornando aptos a amá-las ou a odiá-las. Também Costa (2008) salienta que muitas vezes as mães estudantes acabam atrasando ou até mesmo paralisando o curso por priorizar o cuidado dos filhos. Nesse sentido, Sara argumenta: "Por muitas vezes eu pensei em desistir, outras vezes eu pensei em trancar para poder esperar ela crescer, para eu poder voltar". Assim, para não desistir e nem trancar o curso de graduação, Sarah deixou duas disciplinas para trás, atrasando um ano o término da sua graduação, para então poder dar conta do bebê, da carga horária e das avaliações que a faculdade exige.

Ao mencionar sobre ter planejado ou não o filho durante a graduação, duas mães destacaram que não houve o planejamento, como destacado por Sarah "A minha expectativa 
era engravidar no último semestre da graduação. Mas não foi o que aconteceu, acabou que ela veio antes". Também Lívia afirmou: "Bom não foi decisão não! Aconteceu! Eu pretendia ter, mas só mais para frente".

Por outro lado, a única participante que planejou ter o filho, argumentou: "Como eu tinha recém-casado e meu esposo queria muito um filho, nós namoramos bastante tempo e por causa disso resolvemos..., nós planejamos ter o filho". E justamente a única que planejou ser mãe, acabou desistindo de concluir a educação superior e demostra ter se arrependido de tal decisão "[...] tantas pessoas engravidaram junto comigo eu acho que de todas que engravidaram na minha sala eu fui a única que desisti. [...] eu admiro as mães que persistem, eu queria ter conseguido, hoje me arrependo" (HELOISA).

As três alunas entrevistadas comentaram sobre o período em que estavam afastadas e de licença maternidade, evidenciando que esse período de afastamento tem sido uma fase muito complicada, devido aos contratempos gerados pela maternidade.

Então vieram os trabalhos para fazer em casa e eu acabei fazendo com a bebê no colo! Amamentando! Digitando! [...] Eu recebi as atividades domiciliares quando a bebê tinha acho que quinze dias, tudo eu fazia com ela mamando, com ela as vezes no carrinho do meu lado e eu digitando e estudando.

Ainda segundo Sarah, "Foi bastante tumultuado! Eu acabei fazendo certinho, mas não somou muito! [...] então foi bastante difícil! Foi bastante complicado!"

Lívia enfatiza que não teria conseguido realizar as atividades se não fosse a ajuda de sua mãe para ficar com a bebê "Olha é complicado! Foi bem difícil! Se eu não tivesse a ajuda da minha mãe... Eu não daria conta! não daria mesmo! tenho certeza!” Já Heloisa destaca que por não ter o apoio do marido nesse período, pelo medo e a insegurança, acabou optando por não retornar da licença maternidade: "Eu nem cheguei a retornar! Depois que eu ganhei [a filha], devido às dificuldades, achei melhor desistir, eu nem cheguei a retornar!"

Observa-se nas falas das entrevistadas que em geral a licença maternidade é considerada um período muito difícil, contudo, apesar de todos os contratempos, são capazes de realizar suas atividades. Porém Heloisa relata que não deu conta de conciliar essa fase chegando a colocar impedimentos na continuidade de seus estudos. No que se refere apoio do professor, aos prazos e ao aprendizado em casa fora da universidade, duas participantes da pesquisa responderam:

Esse negócio de ler os textos e ter que resumir na sua cabeça sem o apoio do professor, sem ouvir a explicação do professor, é muito complicado!!! [...] Então eu fiquei muito fora do foco! Eu não sabia o que era importante, eu fiquei muito na dúvida! Para entender em casa! O aprendizado em casa é muito complicado! (LÍVIA)

Foi bastante difícil porque a gente não está lá dentro da sala de aula, não está acompanhando. A maioria dos trabalhos que vieram para eu fazer foram textos que estavam sendo abordados e estudados lá dentro da sala de aula. Então assim..., eu não estava lá! Eu não ouvia o professor falando! Então eu tinha que buscar 
informações, mandei alguns e-mails pedindo orientação, não recebi de volta os emails, então eu tive que estudar sozinha! Foi eu e eu estudando!!! Não tive esse apoio de orientação, eu recebia os e-mails com as propostas de avaliações, porém não tive orientações para fazer (SARAH).

Os relatos evidenciam que as mães estudantes passaram por um processo de grande dificuldade nesse período de afastamento, que influenciou no processo de aprendizagem. Tal fato se deu pela falta de orientação dos professores, tendo em vista que elas estavam ausentes das aulas, e pelas dificuldades em ter que realizar muitas atividades em casa e tão pouco tempo, devido ao prazo limitado que a elas foi disponibilizado, conforme enfatiza Sarah: "Bem difícil!!! Bem difícil mesmo!!! Porque os prazos são curtos! Os prazos são curtos!", Lívia também salienta: "[...] para fazer as atividades em casa era loucura! Loucura! Eu acordava cedo enquanto ela [criança] estava dormindo, eu corria fazer! Se ela acordasse, já era!!! Aí eu não conseguia fazer mais nada!’. Quanto ao retorno para a universidade, após o período de licença maternidade, Sarah declara que:

Todo esse processo da gravidez e da licença maternidade foi difícil, mas o retorno foi pior, eu achei que não ia dar conta! Mas no retorno, nada muda! Do mesmo jeito que é para mãe e para os outros, não tem diferença! Continua igual! A mesma carga horaria, nada flexivel!

Conforme Lima (2007), muitas mães universitárias passam por algum tipo de problema com a chegada de um filho, levando ao trancamento do curso com a intenção de voltar, nem sempre é isso que acontece, pois devido às dificuldades e os obstáculos, acabam desistindo definitivamente ou optando por estudar a distância. Nesse sentido, Heloisa comenta: "[...] eu resolvi trancar a faculdade e comecei um curso no SENAC [...] eu não voltei para a UFMS [...] resolvi fazer outra faculdade, só que faculdade particular e só duas vezes na semana, então para mim eu achei bem viável”.

Diante do que foi exposto, é possível observar que todas passaram por algum tipo de dificuldades pelo fato de se tornarem mães durante a graduação, tendo que se deparar com o período de licença maternidade, realizando atividades domiciliares. Para Nascimento (2004, p. 227), "A licença maternidade tem dois objetivos: possibilitar à mulher a recuperação física do parto e a possibilidade da presença da mãe com a criança em tão importante período". Portanto, fica claro que devemos levar em consideração que o objetivo da licença maternidade é favorecer uma reabilitação diante desse período, bem como proporcionar condições para que a mãe possa ter o contado inicial com o bebê, cuidar, amamentar, buscando preservar sua saúde nessa fase tão delicada. Contudo, a entrevistada Lívia demonstra insatisfação em relação a questão da legislação que as amparam:

Eu creio que deveria ter mais um pouco de tempo, eu acho que poderia estender mais um pouco! Quando eu vim aqui para saber quanto tempo era, eu achava que eram seis meses, quando eu fiquei sabendo quem apenas três!!! É que tem a questão da amamentação, você está amamentando ainda [...] essa legislação, tinha que melhorar muito! Tinha que estender o prazo e também tinha que ser mais favorável para o nosso lado dos trabalhos, né (LIVIA). 
O que percebe diante do relato de Lívia é que não tem como negar que o prazo de licença maternidade para a estudante deveria ser como previsto pela Constituição Federal que é 120 dias e não o da legislação 90 dias. Acontece que no caso de universidades em que os cursos são semestrais e não anuais, como é o caso da UFMS, torna-se mais difícil ampliar o período de afastamento, porque poderia acontecer de a aluna em licença maternidade não acompanhar nenhuma das aulas daquele semestre, comprometendo a qualidade do seu processo de formação acadêmica.

\section{Perspectiva da Professora de Educação Superior - Pedagogia}

Para dar início a discussão, apresenta-se como fundamental destacar o perfil da professora, considerando que a entrevistada atuava por vários anos como docente de educação superior, incluindo o de Pedagogia em que as mães acadêmicas estudavam. Assim, a referida professora acompanhou diversas situações de alunas que precisaram fazer as atividades domiciliares quando se tornaram mães. Além do mais, a própria professora passou pela experiência de ter filhos quando era estudante de graduação e de mestrado.

Trata-se da Professora Gabriela, que tinha 46 anos, casada e três filhos, formada em magistério do nível médio, Pedagogia, Mestrado e Doutorado em Educação. Ao comentar sobre como ela fazia para atender as alunas em licença maternidade, explicou:

[...] então a pessoa entra em licença maternidade eu não mando atividade já seguida que ela entrou não!!! Eu dou um tempo! Eu vejo no semestre qual o tempo do semestre e que a pessoa tem de afastamento, eu não dou logo de início não, eu dou bem depois, as vezes eu mando de uma vez, dependendo da situação mando uma parte [...] E aviso "Vou mandar sim, estava dando um tempo para você curtir mais o bebê, mas vou mandar” (PROF. GABRIELA).

É possível notar que, segundo a Professora, ela oportuniza um prazo maior para que a mãe recupere o desgaste proveniente da gravidez e do nascimento da criança, além de possibilitar condições para que a mãe estudante possa se dedicar ao bebê recém-nascido nos primeiros dias de vida. A participante menciona que com algumas alunas ela tem um diálogo mais frequente, já com outras não: "Olha de modo geral, algumas a gente conversa mais, se abre mais, fala mais, outras menos né!?” (PROF. GABRIELA).

Em relação à contribuição dos professores para com essas alunas, a Prof. Gabriela discorre: "[...] olha eu acho que acaba ajudando sim! No sentido de que a gente procura ter mais paciência, elas têm que se adaptar e as vezes têm aquela insegurança”, argumentando que na época em que ela estudava, esse apoio não havia nem pelos professores, nem pela universidade.

Pela a minha experiência aqui da universidade que eu estou desde 2009 eu acho que no geral os professores eles são mais compreensivos, colaboram mais que antes, por exemplo, eu penso que eu não tive colaboração nenhuma! Nenhuma! Na verdade, foi até dificultado! Não tive colaborarão! (PROF. GABRIELA). 
Quanto à contribuição dos docentes em seu processo de formação acadêmica, a Prof. Gabriela salienta que: “[...] os professores em si, eu não achei que facilitaram e contribuíram não! Deviam pensar 'Por que que engravidou? Por que não acabou de estudar primeiro?'”.

No que se refere ao apoio dos docentes com essas alunas, a Prof. Gabriela relata que hoje em dia ela vê e também observa em outros professores que eles se colocam mais na condição da aluna, tentam colaborar, não no sentido de ficar mais fácil, mas sim de tentar facilitar para que essas não desistam da educação superior. "A maioria dos professores eu acredito que contribuem, até para que as pessoas não parem o curso, para que elas [mães estudantes] continuem e concluam o curso". A Prof. Gabriela compara como era em sua época e declara: "Eu vejo diferença, vejo que hoje está mais fácil e mais tranquilo de lidar com essa situação do que quando foi comigo na década de 1990”.

Sobre as experiências da maternidade vivenciadas pela professora, ainda quando era aluna, a Prof. Gabriela conta que não tinha planos de engravidar durante a graduação, que o objetivo era estudar e trabalhar primeiro, porém não foi o que aconteceu. "Olha quando eu entrei na graduação, no curso de Pedagogia, a minha intenção não era ter filhos, mas sim me formar primeiro".

Mediante o relato da Prof. Gabriela, no que se refere a decisão da maternidade durante a graduação, percebe-se que tanto a docente, quanto muitas alunas de Pedagogia da UFMS, não planejaram a gravidez, mas no caso da referida professora, ela optou por trancar o curso por um tempo.

Como eu não tinha planejado acabou acontecendo. No ano seguinte eu tranquei porque eu queria trabalhar e eu achava que eu não daria conta de ter um bebe, de trabalhar e de estudar. Eu falei "Eu não vou dar conta de tudo! Eu tenho que escolher alguma coisa". Então eu optei por trancar o curso, para cuidar da criança e trabalhar fora (PROF. GABRIELA).

A atitude da professora, assim como da aluna Sarah, que não chegou a trancar totalmente, mas diminuiu o número de disciplinas, postergando assim o término da educação superior, estão relacionadas com os pressupostos de Costa (2008) e Sant'Anna (2006), por afirmar que algumas mães acadêmicas, diante das dificuldades vivenciadas após o nascimento do bebê, decidem por atrasar, paralisar ou fazer o curso a distância, a fim de conciliar ambos os papeis, inerente à maternidade e vida de estudante.

Ainda sobre sua experiência nesse período, a professora entrevistada recorda do momento em que fez o mestrado, que para ela foi uma das experiências mais fortes, pois engravidou do segundo filho e mais uma vez não tinha sido planejado. Então pediu licença maternidade e lhe foi negado.

Fui conversar na universidade e disse: "Eu vim aqui fazer a matricula e conversar para ver se eu tenho algum direito a algum afastamento inicial, pelo menos nos primeiros momentos". Ele [coordenador do curso] falou: "Não! Não tem não! Ou você vem cursar ou você passa a vaga para outra pessoa, não tem licença maternidade na pós-graduação não!” (PROF. GABRIELA). 
Observa-se na resposta da professora que, apesar de a Lei $\mathrm{n}^{\circ} 6.202 / 75$ estabelecer o direito ao regime domiciliar para estudantes grávidas, ela teve esse direito negado. No caso da Pós-Graduação, talvez no período em que a Prof. Gabriela cursou o mestrado não havia regulamentação, visto que na atualidade, a Portaria CAPES no 248, de 19 de dezembro de 2011 estabelece que mesmos as bolsistas têm direito a prorrogar a bolsa por mais quatro meses, correspondente ao período de licença maternidade:

Art. $1^{\circ}$ - Os prazos regulamentares máximos de vigência das bolsas de estudo no país e no exterior, iguais ou superiores a 24 (vinte e quatro meses), destinadas à titulação de mestres e doutores, poderão ser prorrogados por até 4 (quatro) meses, se comprovado o afastamento temporário das atividades da bolsista, provocado pela ocorrência de parto durante o período de vigência da respectiva bolsa (BRASIL, 2011).

Ao analisar os relatos da Prof. Gabriela com e comparar com as três mães acadêmicas entrevistadas, é possível notar que todas tiveram contratempos relacionados à maternidade e todas consideram que essa fase resulta em dificuldades para conciliar as atividades acadêmicas com o bebê e a amamentação. Ainda existe o fato de ter alguém para cuidar da criança, para poder estudar.

Então, isso foi muito difícil para mim porque eu deixava ela com doze dias [...] Além disso, eu sofria porque eu não tinha leite, eu à amamentava, mas não tinha para tirar e deixar para ela tomar depois. Então isso foi uma coisa que eu tive muita dificuldade de conciliar: a amamentação com os horários. Além disso, tinha a dificuldade de quem cuidar quando eu ir estudar (PROF. GABRIELA).

Por meio dos relatos da professora entrevistada, fica explícito que tornar-se mãe durante a graduação nem sempre foi fácil, ficando visível que tanto nos dias atuais como anteriormente, a maternidade é uma fase que causa contratempos na vida pessoal, profissional e acadêmica das mulheres. Mas que assim como a maioria das alunas de Pedagogia do CPNV/UFMS que se tornam mães durante a graduação, a Prof. Gabriela também conseguiu concluir o seu processo de formação e posteriormente se tornou mestre e doutorada, indicando que as mulheres, apesar das dificuldades, têm conseguido conciliar as atividades relativas à maternidade, estudos, profissão, entre tantas outras.

\section{Considerações Finais}

Diante das questões que deram origem ao presente estudo, a partir da pesquisa realizada evidencia-se que há uma série de concepções a respeito da realidade de mulheres que se tornaram mães durante a educação superior, sinalizando que a ideia de ser mãe universitária não é tão simples, pois existem diversas circunstancias que tornam a vida dessas mulheres mais desafiadoras e acumuladas de atribuições.

Diante dos dados obtidos, foi possível constatar que, apesar de as mulheres estarem conquistando o espaço no mundo acadêmico, existem muitas dificuldades vivenciadas pelas mães estudantes, que ficam acumuladas de funções, por ter que conciliar a educação superior 
com a maternidade. Além disso, existe o desafio de ter que realizar as atividades acadêmicas em casa, cuidar do bebê e desempenhar outras atividades domésticas ao mesmo tempo. Algumas estudantes optam por cursar menos disciplinas ou trancar o curso temporariamente, para então retornar posteriormente, sem abrir mão do objetivo de ter um curso superior.

A partir dos dados obtidos por meio da pesquisa quantitativa, fica evidente que por maiores que sejam as dificuldades enfrentadas pelas mães acadêmicas, a maioria consegue conciliar e concluir o curso, mesmo diante do nascimento do filho. Assim, entre o total de 34 mulheres que se tornaram mães durante a graduação em Pedagogia do CPNV/UFMS, apenas 3 ou $8,82 \%$ desistiram do curso, podendo ser considerado um número baixo, já que 23 do total ou $67,64 \%$ do total concluíram e 11 ou $23,52 \%$ continuavam em andamento.

Em relação a postura da universidade, durante os três meses de licença maternidade, os professores enviam atividades domiciliares, mas as alunas consideram pouco tempo de afastamento. No entanto, nota-se um avanço em relação ao período em que a professora entrevistada passou pela experiência de se tornar mãe enquanto estudava.

Vale ressaltar que o presente estudo não teve o intuito de esgotar a temática aqui abordada, uma vez que é importante haver novas pesquisas na área, a fim de melhor entender realidade, bem como as dificuldades vivenciadas por mulheres que se tornam mães enquanto cursam a educação superior, bem como formas de contribuir com a permanência dessas mulheres na universidade.

Dessa maneira, a partir da pesquisa realizada, torna-se evidente que conciliar a vida de mãe acadêmica com a universidade, além de diversas outras atribuições, não é tarefa fácil, mas apesar dos desafios vivenciados, a maioria das mães estudantes de Pedagogia do CPNV/UFMS demonstra determinação, por conseguir atingir o objetivo de concluir a educação superior.

\section{Referências}

AZEVEDO, Kátia Rosa; ARRAIS, Alessandra da Rocha. O mito da mãe exclusiva e seu impacto na depressão pós-parto. Psicologia: reflexão e crítica, Porto Alegre, v. 19, n. 2, p. 269-276, 2006.

BADINTER, Elisabeth. Um amor conquistado: O mito do amor materno. Rio de Janeiro, RJ: Nova Fronteira, 1985.

BARBOSA, Patrícia Zulato; ROCHA-COUTINHO, Maria Lúcia. Maternidade: novas possibilidades, antigas visões. Psicologia Clínica, Rio de Janeiro, v. 19, n. 1, p. 163-185, 2007.

BEE, Helen. O ciclo vital. Tradução Regina Garcez. Porto Alegre: Artmed, 1997. 
BRASIL, Lei $\mathbf{n}^{\mathbf{0}}$ 6.202, de 17 de abril de 1975. Atribui à estudante em estado de gestação o regime de exercícios domiciliares. 1975. Disponível em: http://www.planalto.gov.br/ ccivil_03/LEIS/1970-1979/L6202.htm. Acesso em: 23 fev. 2018.

BRASIL, Portaria ${ }^{\circ}$ 248, de 19 de dezembro de 2011. Estabelece normas sobre a prorrogação de bolsas por quatro meses para mulheres grávidas que cursam mestrado e doutorado. Disponível em: http://www.camara.gov.br/sileg/integras/1392686.pdf. Acesso em: 27 set. 2018.

COSTA, Luiz Paulo. Mães universitárias ainda são ‘órfãs' na UFS. Blog do Contexto Online UFS. Blog do Jornal Laboratório do Departamento de Artes e Comunicação Social da Universidade Federal de Sergipe, 21 maio 2008. Disponível em: http://blog-contextoufs.blogspot.com.br/2008/05/mes-universitrias-ainda-so-rfs-na-ufs_7495.html. Acesso: 29 set. 2018.

COSTA, Jurandir Freire. Ordem médica e norma familiar. Rio de Janeiro: Edições Graal, 1983.

CRESWELL, Jonh W. Projeto de pesquisa: métodos qualitativo, quantitativo e misto. 2. ed. Porto Alegre: Bookman, 2010.

FALCKE, Denise; WAGNER, Adriana. Mães e madrastas: mitos sociais e autoconceito. Estudos de Psicologia, Campinas, v. 5, n. 2, p. 421-441, 2000.

FERREIRA, Luan Angelino; SILVA, Fernando Guimarães Oliveira da. A pedagogia tem gênero? O pedagogo cisgênero na educação da infância. Educação Online, Rio de Janeiro, n. 26, p. 23-45, set./dez. 2017.

GONÇALVES, Josiane Peres. Ciclo vital: início, desenvolvimento e fim da vida humana, possíveis contribuições para educadores. Contexto \& Educação, Ijuí, v. 31, n. 98, p. 79-110, jan./abr., 2016.

GUEDES, Moema de Castro. A presença feminina nos cursos universitários e nas pósgraduações: desconstruindo a ideia da universidade como espaço masculino. História, Ciências, Saúde - Manguinhos, Rio de Janeiro, v.15, p.117-132, jun. 2008.

LIMA, Lunélia. Como é ter um filho durante o período acadêmico? É possível continuar os estudos? Jornal laboratório do curso de Comunicação Social da Universidade Federal do Espírito Santo, 7 nov. 2007. Disponível em: http://universoufes.wordpress.com/2007/11/07/maes-universitarias/. Acesso em: 26 fev. 2018.

MANSUR, Luci Helena Baraldo. Experiências de mulheres sem filhos: a mulher singular no plural. Psicologia: ciência e profissão, Brasília, v. 23, n. 4, p. 2-11, 2003.

MATOS, Maria Izilda; BORELLI, Andrea. Espaço feminino no mercado produtivo. In: PINSKY, Carla Bassanezi; PEDRO, Joana Maria (Org.). Nova história das mulheres no Brasil. São Paulo: Contexto, 2012, p. 126-147. 
NASCIMENTO, Amauri Mascaro. Iniciação ao direito do trabalho. 30. ed. - São Paulo: LTr, 2004.

PARKER, Rozika. A mãe dividida: A experiência da ambivalência na maternidade. Rio de Janeiro, RJ: Rosa dos Tempos, 1997.

PRAVAZ, Suzana. Três Estilos de Mulher. Rio de Janeiro: Paz e Terra, 1981.

RODRIGUES, Daniel Gustavo, FERREIRA, Luiz Antônio Miguel. Em busca da afetividade do direito à Educação: a Licença Gestante para estudante. Científica: ciências jurídicas e empresariais, Londrina, v. 9, n. 1, p. 13-18, mar. 2008.

SAMPIERI, Roberto Hernández; COLLADO, Carlos Fernández; LUCIO, Pilar Baptista. Metodologia de pesquisa. São Paulo: Mc Graw Hill, 2006.

SANT’ANNA, Emilio. Sobram 71\% das vagas de cursos à distância. Associação Brasileira de Educação à Distância. São Paulo, 15 dez 2006. Disponível em:

http://www.abed.org.br/site/pt/midiateca/noticias_ead/230/2006/12/sobram_71_das_vagas_de _cursos_a_distancia_. Acesso em: 26 fev. 2018.

SCOTT, Ana Silvia. O caleidoscópio dos arranjos familiares. In: PINSKY, Carla Bassanezi; PEDRO, Joana Maria (Org.). Nova história das mulheres no Brasil. São Paulo: Contexto, 2012, p. 15-42.

TOURINHO, Julia Gama. A mãe perfeita: idealização e realidade - Algumas reflexões sobre a maternidade. IGT na Rede, Rio de Janeiro, v. 3, n. 5, p. 1-35, 2006.

TOURO, Rolando. Biodanza. São Paulo: Olavobrás, 2002.

UFMS, Universidade Federal de Mato Grosso do Sul. Conselho Universitário. Resolução no 65 de 28 de agosto de 2008. Aprova a criação e implantação de cursos de graduação presenciais nos Câmpus de Naviraí (CPNV) e Ponta Porã (CPPP), a partir do ano letivo de 2009 e dá outras providências. Campo Grande: Conselho Universitário, 2008.

UFMS, Universidade Federal de Mato Grosso do Sul. Conselho Universitário. Resolução no 104 de 16 de junho de 2010. Regulamento de Exercícios Domiciliares, para os acadêmicos dos Cursos de Graduação, presenciais, da Fundação Universidade Federal de Mato Grosso do Sul. Campo Grande: Conselho de Graduação, 2010. 